\title{
Long-Term Antagonism of $\kappa$ Opioid Receptors Prevents Escalation of and Increased Motivation for Heroin Intake
}

\author{
Joel E. Schlosburg, Timothy W. Whitfield Jr, Paula E. Park, Elena F. Crawford, Olivier George, Leandro F. Vendruscolo, \\ and George F. Koob \\ Committee on Neurobiology of Addictive Disorders, The Scripps Research Institute, La Jolla, California 92037
}

\begin{abstract}
The abuse of opioid drugs, both illicit and prescription, is a persistent problem in the United States, accounting for $>1.2$ million users who require treatment each year. Current treatments rely on suppressing immediate withdrawal symptoms and replacing illicit drug use with long-acting opiate drugs. However, the mechanisms that lead to preventing opiate dependence are still poorly understood. We hypothesized that $\kappa$ opioid receptor (KOR) activation during chronic opioid intake contributes to negative affective states associated with withdrawal and the motivation to take increasing amounts of heroin. Using a $12 \mathrm{~h}$ long-access model of heroin self-administration, rats showed escalation of heroin intake over several weeks. This was prevented by a single high dose $(30 \mathrm{mg} / \mathrm{kg})$ of the long-acting KOR antagonist norbinaltorphimine (nor-BNI), paralleled by reduced motivation to respond for heroin on a progressive-ratio schedule of reinforcement, a measure of compulsive-like responding. Systemic nor-BNI also significantly decreased heroin withdrawal-associated anxiety-like behavior. Immunohistochemical analysis showed prodynorphin content increased in the nucleus accumbens core in all heroin-exposed rats, but selectively increased in the nucleus accumbens shell in long-access rats. Local infusion of nor-BNI ( $4 \mu \mathrm{g} / \mathrm{side})$ into accumbens core altered the initial intake of heroin but not the rate of escalation, while local injection into accumbens shell selectively suppressed increases in heroin intake over time without altering initial intake. These data suggest that dynorphin activity in the nucleus accumbens mediates the increasing motivation for heroin taking and compulsive-like responding for heroin, suggesting that KOR antagonists may be promising targets for the treatment of opioid addiction.
\end{abstract}

\section{Introduction}

Opioid use and dependence are growing problems affecting 35 million people worldwide (United Nations Office for Drug Control and Crime Prevention, 2012). Current pharmacotherapeutics focus on reducing immediate withdrawal symptoms or using long-term $\mu$ opioid receptor agonists to prevent withdrawal. Negative somatic and affective consequences of withdrawal are considered a driving force in continued use of opioids (Koob, 2008). Understanding neurotransmitter systems that mediate the negative motivational effects of withdrawal may improve therapeutic strategies in addiction treatment. Prominent among these neurotransmitter systems is the $\kappa$ opioid receptor (KOR) system.

The KOR is endogenously activated by the peptide dynorphin (Chavkin et al., 1982), cleaved from its precursor, prodynorphin.

Received May 10, 2013; revised Oct. 4, 2013; accepted 0ct. 30, 2013.

Author contributions: J.E.S., T.W.W.J., E.F.C., O.G., and G.F.K. designed research;J.E.S., T.W.W.J.,P.E.P., and L.F.V. performed research; J.E.S., P.E.P., E.F.C., and L.F.V. analyzed data; J.E.S., T.W.W.J., and G.F.K. wrote the paper.

This work was supported by the Pearson Center for Alcoholism and Addiction Research at The Scripps Research Institute and National Institutes of Health Grants DA004043 and AA007456. We acknowledge the technical assistance of Andrew Pham and lyung Michelle Jung as a part of their independent research internships at the University of California, San Diego. We also acknowledge Michael Arends and Remi Martin-Fardon for assistance in manuscript preparation and editing. nor-BNI was generously provided by Kevin Gormley, National Institute on Drug Abuse. This is manuscript \#24033 from The Scripps Research Institute.

The authors declare no competing financial interests.

Correspondence should be addressed to Joel Schlosburg, PhD, Committee on the Neurobiology of Addictive Disorders, The Scripps Research Institute, 10550 North Torrey Pines Road, SP30-2400, La Jolla, CA 92037. E-mail: schlos@scripps.edu.

DOI:10.1523/JNEUROSCI.1979-13.2013

Copyright $\odot 2013$ the authors $\quad 0270-6474 / 13 / 3319384-09 \$ 15.00 / 0$
Activation of KORs leads to negative emotional-like states, reflected by conditioned place aversion (Shippenberg and Herz, 1986) and increased intracranial self-stimulation thresholds (Todtenkopf et al., 2004). This is closely paralleled by clinical reports that KOR agonists are dysphoric (Pfeiffer et al., 1986; Rimoy et al., 1994). Conversely, KOR antagonists produce antidepressant-like effects (Newton et al., 2002; Mague et al., 2003). Notably, KOR antagonism effectively reversed anxietylike behavior associated with drug withdrawal (Chartoff et al., 2012; Valdez and Harshberger, 2012).

Evidence also suggests interactions between heroin use and the dynorphin-KOR system. KOR activity plays a significant role in stress-induced reinstatement of drug-seeking behavior across several drugs of abuse, including heroin (Redila and Chavkin, 2008; Zhou et al., 2013). Polymorphisms in genes that encode the human KOR (Yuferov et al., 2004; Gerra et al., 2007) and prodynorphin (Clarke et al., 2012) have been associated with increased risk for opioid addiction. Additionally, animal studies have demonstrated region-specific increases in gene expression of the precursor preprodynorphin (Tjon et al., 1997), leading to increased levels of dynorphin, following passive administration of morphine (Nylander et al., 1995) and heroin (Weissman and Zamir, 1987). Expression of the dynorphin precursor prodynorphin is also increased during the anticipation of heroin (Cappendijk et al., 1999) and following heroin self-administration (Solecki et al., 2009).

One apparent mechanism by which dynorphin alters the aversive/rewarding aspects of drug intake is through suppression of 


\section{Experiment 1: Systemic nor-BNI}

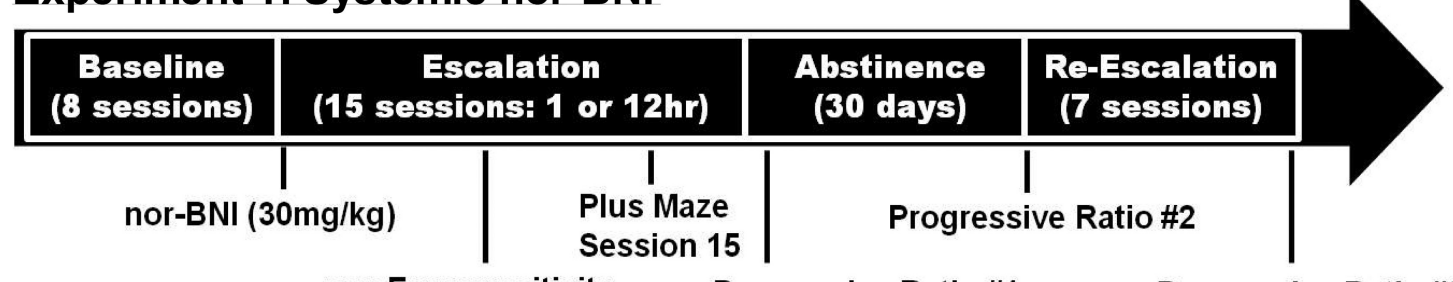

von Frey sensitivity

Session 1, 4, 7, 10, 14

Progressive Ratio \#1

Progressive Ratio \#3

\section{Experiment 2: Prodynorphin IHC}

\begin{tabular}{|c|c|c|}
\hline $\begin{array}{c}\text { Baseline } \\
\text { (8 sessions) }\end{array}$ & (15 sessions: 1 or 12hr) & $\begin{array}{c}\text { Perfusion, } \\
\text { extraction }\end{array}$ \\
\hline
\end{tabular}

\section{Experiment 3 \& 4: Nucleus Accumbens Shell/Core nor-BNI}

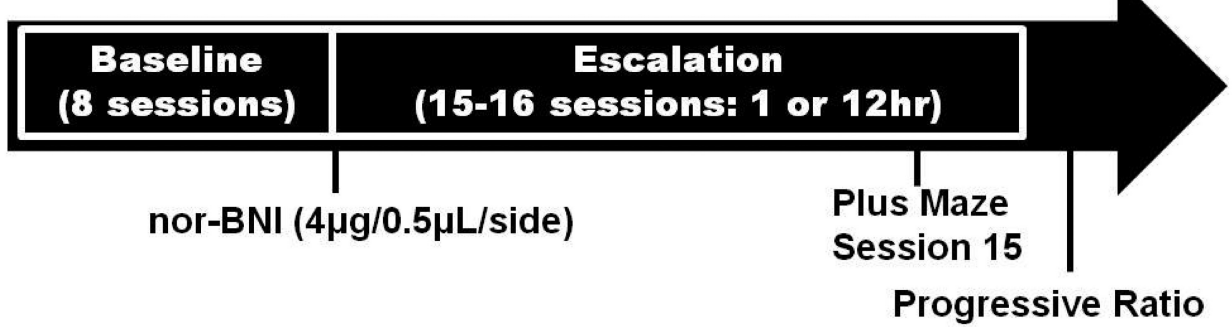

Figure 1. Schematic representation of heroin self-administration timelines for the three experimental groups that comprised the entire study. Additional treatments and behavioral testing, beyond FR heroin self-administration, are noted below the timelines to highlight when they were administered.

dopamine release in the nucleus accumbens (Newton et al., 2002; Zapata and Shippenberg, 2006). Xi et al. (1998) demonstrated that the KOR agonist U50,488H suppressed dopamine release in the nucleus accumbens in heroin self-administering rats, resulting in increased immediate heroin intake. Conversely, the KOR antagonist nor-binaltorphimine (nor-BNI) enhanced and prolonged dopamine. However, nor-BNI did not significantly alter stable self-administration of limited-access heroin (Negus et al., 1993), suggesting KOR antagonism does not alter the rewarding value of the drug in nondependent subjects.

We hypothesized that escalation of heroin intake produces increased expression of prodynorphin in the nucleus accumbens, promoting further heroin intake. Therefore, administration of the KOR antagonist nor-BNI both systemically and directly in the nucleus accumbens would prevent the escalation of heroin as demonstrated in animal models of alcohol dependence (Walker and Koob, 2008; Nealey et al., 2011). We also examined concurrent adaptations that may contribute to continued opioid use, such as withdrawal-induced anxiety-like behavior and tactile hypersensitivity (Edwards et al., 2012; Barbier et al., 2013).

\section{Materials and Methods}

Subjects. One hundred fourteen adult male Wistar rats (Charles River), weighing 225-275 $\mathrm{g}$ at the beginning of the experiments, were housed in groups of $2-3$ per cage in a temperature-controlled $\left(22^{\circ} \mathrm{C}\right)$ vivarium on a $12 \mathrm{~h} \mathrm{light/dark} \mathrm{cycle} \mathrm{(lights} \mathrm{on} \mathrm{at} \mathrm{6:00} \mathrm{A.M.)} \mathrm{with} \mathrm{ad} \mathrm{libitum} \mathrm{access} \mathrm{to}$ food and water. The animals were allowed to acclimate to the animal facility for at least $7 \mathrm{~d}$ before surgery. All of the procedures adhered to the National Institutes of Health Guide for the Care and Use of Laboratory Animals and were approved by the Institutional Animal Care and Use Committee of The Scripps Research Institute. Eighty-eight rats concluded the studies, with six removed because of complications with jug- ular catheters, four removed because of subsequent catheter patency failures, and two removed because of improper intracranial placements discovered after the studies concluded (see below).

Intravenous catheterization surgery. The rats were anesthetized with $1.5-2.5 \%$ isoflurane and prepared with chronic intravenous Silastic catheters (Dow Corning) into the right jugular vein. The catheter was secured to the vein with suture thread and passed subcutaneously to exit dorsally on the animal's back. After surgery, the catheters were flushed daily with $0.2 \mathrm{ml}$ of a sterile solution that contained heparinized (30 United States Pharmacopeia units $/ \mathrm{ml}$ ) saline and the antibiotic cefazolin. The rats were allowed to recover for $7 \mathrm{~d}$ before behavioral testing.

Self-administration procedure. Self-administration sessions were conducted in standard operant conditioning chambers (Med Associates). Self-administration sessions were conducted as previously described (Vendruscolo et al., 2011). Briefly, the rats were trained to press one of two levers (i.e., the active lever) on a fixed-ratio (FR) 1 schedule of reinforcement, in which each lever press resulted in fluid delivery to obtain $0.1 \mathrm{ml}$ of heroin $(60 \mu \mathrm{g} / \mathrm{kg} /$ infusion $)$ in $1 \mathrm{~h}$ sessions. Reinforced responses were followed by a $20 \mathrm{~s}$ timeout period, in which a cue-light above the active lever was turned on, and lever presses did not result in additional injections. During the acquisition of heroin self-administration, food and water were not available to the rats while in the test chambers. After the acquisition of heroin self-administration, the rats were split into two groups matched for the number of lever presses during the last three sessions of the acquisition phase and were given $1 \mathrm{~h}$ short access (ShA) or $12 \mathrm{~h}$ long access (LgA) to heroin self-administration. In this phase, all of the groups were allowed to nosepoke for food and water on an FR3 schedule while heroin was available. The ShA groups were tested just before the LgA sessions, which occurred during the dark phase of the light/dark cycle. The sessions typically occurred $5 \mathrm{~d}$ per week, with $2 \mathrm{~d}$ of abstinence. The durations of the self-administration phases for each group are presented in Figure 1.

Experiment 1: effect of systemic nor-BNI on heroin escalation. Systemic nor-BNI (National Institute on Drug Abuse, Bethesda, MD) was adminis- 
tered in saline in an injection volume of $2 \mathrm{ml} / \mathrm{kg}$. To prevent early $\mu$ opioid receptor activity from interfering with heroin intake (Munro et al., 2012), $2 \mathrm{~d}$ were allowed to elapse between the injection of systemic nor-BNI $(30 \mathrm{mg} / \mathrm{kg}$, s.c.) and beginning of the escalation self-administration sessions, both dose and timeline previously shown effective for studies of cocaine use in rats (Wee et al., 2009; Chartoff et al., 2012). The rats were given a day off after their final escalation session and were then tested in a $6 \mathrm{~h}$ progressive-ratio (PR) session. Each successive infusion required greater lever-pressing requirements, with the following PR schedule: $1,1,2,2,3,3,4,4,5,5,6,6,7,7$, $8,8,9,9,10,11,12,13,14$, etc. The schedule for the PR sessions is presented in Figure 1.

Mechanical nociceptive testing was conducted during withdrawal, just before subsequent self-administration Sessions 1, 4, 7, 10, and 14 according to previously described methods (Edwards et al., 2012). A group of drug-naive rats that were handled but did not undergo surgery or enter the self-administration chambers were tested alongside the ShA and LgA groups. Briefly, the rats were acclimated for $15 \mathrm{~min}$ in elevated cages with a wire mesh floor. A series of von Frey filaments were applied perpendicularly to the plantar surface of the hindpaw for $3 \mathrm{~s}$. A sharp withdrawal of the hindpaw indicated a positive response. The stimulus was incrementally increased until a positive response occurred and then decreased until a negative result occurred to determine a pattern of responses to apply to the statistical method of Dixon. Baseline mechanical nociceptive thresholds were similar to those reported for the ages of the rats used in this study, with a cutoff of $100 \mathrm{~g}$ maximal force (Edwards et al., 2012).

The elevated plus maze test was performed during withdrawal, just before self-administration session 15 ( $12 \mathrm{~h}$ withdrawal, LgA; $23 \mathrm{~h}$ withdrawal, ShA). The apparatus had four elevated arms $(52 \mathrm{~cm}$ above the floor), $50 \mathrm{~cm}$ long and $10 \mathrm{~cm}$ wide, set in a cross-like configuration, with two opposite arms enclosed by $40-\mathrm{cm}$-high opaque walls and two open arms with an edge ( $1 \mathrm{~mm}$ thick and $5 \mathrm{~mm}$ high). A central platform at their intersection $(10 \times 13.5 \mathrm{~cm})$ permitted access to any of the four arms. Illumination of the central platform was $<10$ lux. Each rat was placed on the central platform facing an open arm. The behavior of each animal was recorded for $5 \mathrm{~min}$. The time spent on the open and closed arms and percentage of time spent on the open arms (percentage openarm time) relative to the time spent on both the open and closed arms were used as an index of anxiety-like behavior.

Experiment 2: prodynorphin immunohistochemistry. Separate groups of rats were subjected to the same ShA and LgA self-administration conditions as the rats in Experiment 1, but they received only heroin and no further drug treatments. The drug-naive group from Experiment 1, which was subjected to the von Frey test but received no heroin, no nor-BNI, and no saline, was also processed for immunohistochemistry (IHC). Rats were perfused, and brains extracted, directly before their respective next scheduled self-administration session ( $23 \mathrm{~h}$ withdrawal ShA, $12 \mathrm{~h}$ withdrawal LgA) to examine prodynorphin content directly before drug-taking. Following administration of 35\% w/v chloral hydrate $(2 \mathrm{ml} / \mathrm{kg}, 70 \mathrm{mg} / \mathrm{kg})$, the animals were transcardially perfused, first with saline and then with a $4 \%$ paraformaldehyde solution. Brains were postfixed at $4^{\circ} \mathrm{C}$ in paraformaldehyde for $6 \mathrm{~d}$ following extraction and cryoprotected in $30 \%$ sucrose for 3 weeks before freezing at $-80^{\circ} \mathrm{C}$. The brains were then sectioned into $40 \mu \mathrm{m}$ slices and preserved in PBS that contained $1 \%$ sodium azide. All of the experimental groups were processed in parallel using the same immunohistochemical procedures. Free-floating sections were rinsed in PBS, incubated for $30 \mathrm{~min}$ in $1 \%$ hydrogen peroxide PBS solution to quench endogenous peroxidase activity, rinsed several times in PBS, and incubated in a blocking solution that contained $0.1 \%$ bovine serum albumin (BSA), 5\% normal donkey serum, and $0.3 \%$ Triton X-100 in PBS for $60 \mathrm{~min}$. The sections were incubated in rabbit anti-prodynorphin polyclonal antibody diluted 1:1000 (Abcam) in PBS that contained 0.5\% Tween 20, 0.1\% BSA, and $5 \%$ normal donkey serum for $24 \mathrm{~h}$ at $4^{\circ} \mathrm{C}$.

After incubation in the primary antibody, the sections were rinsed three times for $10 \mathrm{~min}$ in PBS and incubated in ImmPRESS anti-rabbit IgG peroxidase-linked secondary antibody (Vector Labs). Immunoreactivity was visualized using a DAB substrate kit (Vector Labs). After several rinses in PBS, the sections were mounted on coated glass slides, air dried, dehydrated through a series of graded ethanols and clearing agent, and permounted. The sections were analyzed under bright-field microscopy using a Zeiss Axiophot microscope equipped with a Zeiss AxioCamMRc digital camera for photography. Nucleus accumbens images were all taken at $2.5 \times$ magnification at one time to maintain identical lighting intensity and color balance. Averaged integrated density (i.e., integrated gray density divided by the selected area) for the nucleus accumbens core and shell was determined using inverted color images in ImageJ software (National Institutes of Health), corrected to background using the anterior commissure.

Experiment 3: nucleus accumbens shell nor-BNI infusion. Within $2 \mathrm{~d}$ of the final heroin training session, the rats were anesthetized with $1.5-2.5 \%$ isoflurane and placed in a stereotaxic frame (Kopf Instruments). A custom 33 gauge hypodermic injector, connected via Tygon tubing to a $10 \mu \mathrm{l}$ syringe (Hamilton) and protected with a 26 gauge guide, was inserted into the medial shell of the nucleus accumbens (anterior-posterior, +1.7 $\mathrm{mm}$; medial-lateral, $\pm 0.8 \mathrm{~mm}$; dorsal-ventral, $-7.2 \mathrm{~mm}$ from bregma). Infusions of artificial CSF ( $\mathrm{aCSF}$ ) or nor-BNI ( $4 \mu \mathrm{g} / \mathrm{side})$ were controlled by a programmable syringe pump (KD Scientific) to deliver $0.5 \mu \mathrm{l} /$ side over a 2 min period, with the injectors kept in place for an additional minute to allow for drug diffusion. Skulls were sealed with bone wax (Ethicon), and the incision was sutured.

The rats were allowed to recover for $4 \mathrm{~d}$ and then escalated for 15 sessions. The elevated plus maze test was conducted just before the last escalation session as in Experiment 1. A PR test was performed the day following the final escalation session. The rats were killed, and the brains were snap frozen. The brains were sectioned on a cryostat to verify the placement of $100 \mu \mathrm{m}$ coronal sections under a light microscope. Only animals with correct cannula placements were used for the statistical analysis. Two animals were removed from the nucleus accumbens shell study because of incorrect injector placement.

Experiment 4: nucleus accumbens core nor-BNI infusion. The experimental design was identical to that of Experiment 3 except that only LgA groups were tested due to lack of ShA effects in prior experiments. Rats underwent identical escalation procedures over 16 sessions. Rats underwent similar stereotaxic surgery as in Experiment 3 except a more lateral target injection site targeting the accumbens core (anterior-posterior, $+1.7 \mathrm{~mm}$; medial-lateral, $\pm 1.3 \mathrm{~mm}$; dorsal-ventral, $-7.2 \mathrm{~mm}$ from bregma). Infusions of aCSF or nor-BNI ( $4 \mu \mathrm{g} / \mathrm{side})$ were controlled by a programmable syringe pump (KD Scientific) to deliver $0.5 \mu \mathrm{l} /$ side over a $2 \mathrm{~min}$ period, with the injectors kept in place for an additional minute to allow for drug diffusion. Skulls were sealed with bone wax (Ethicon), and the incision was sutured. The brains were sectioned on a cryostat to verify the placement of $100 \mu \mathrm{m}$ coronal sections under a light microscope. Only animals with correct cannula placements were used for the statistical analysis. One animal was removed from the nucleus accumbens core study because of incorrect injector placement.

Statistical analysis. All of the data are expressed as means and SEs of the mean (SEM). The data were analyzed using two-way ANOVA, with treatment (saline and nor-BNI) and access (ShA and LgA) as the betweensubjects factors, or two-way repeated-measures ANOVA, with group (ShA and LgA) and treatment (saline and nor-BNI) as the betweensubjects factors and session as the within-subjects factor. Following significant effects in the ANOVA, post hoc comparisons were made using the Tukey's or Dunnett test as appropriate. The probability for a Type 1 error for all significance testing was set at $p \leq 0.05$.

\section{Results}

\section{Experiment 1: systemic KOR antagonism prevents escalation} of heroin intake

Pretreatment with nor-BNI before the first LgA session blocked the development of escalation of heroin intake. Both LgA groups showed similar heroin intake in the initial $12 \mathrm{~h}$ sessions, but only the saline-treated LgA group showed significant increases in heroin intake over time (Fig. 2a). nor-BNI significantly reduced heroin intake selectively in LgA rats across time (session $\times$ treatment interaction: $\left.F_{(1,238)}=1.96, p<0.05\right)$. Saline-treated LgA rats showed significantly increased intake from Session 11 onward compared with Session 1. nor-BNI-treated LgA rats showed no 

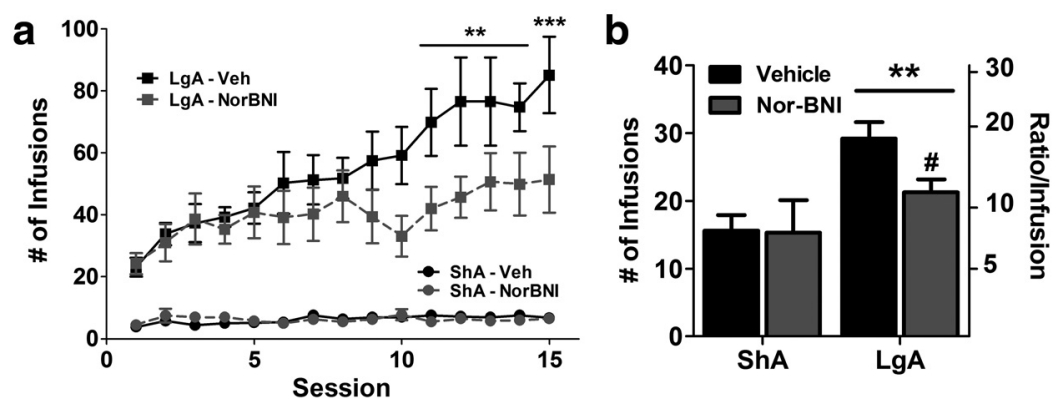

Figure 2. Pretreatment with the $\kappa$ opioid receptor antagonist nor-BNI prevented the escalation of heroin intake with long access. $\boldsymbol{a}$ Rats exposed to long-access heroin self-administration significantly increased their intake of heroin across 15 escalation sessions. Pretreatment with nor-BNI ( $30 \mathrm{mg} / \mathrm{kg}$, s.c.) $2 \mathrm{~d}$ before the initial session did not alter initial heroin intake but prevented the increase in heroin intake across the 15 -session period. $\boldsymbol{b}$, Motivation for heroin, measured by PR performance, was selectively reduced by nor-BNI ( $30 \mathrm{mg} / \mathrm{kg}$, s.c.) in LgA rats. Following a period of escalation, LgA rats showed higher number of heroin infusions under PR schedule, an effect that was significantly reduced by nor-BNI. The left axis indicates the overall infusions of heroin. The right axis indicates the corresponding ratio of presses per infusion (i.e., "breakpoint"). $n=5-8$ per group. $\boldsymbol{a},{ }^{* *} p<0.01,{ }^{* * *} p<0.001$, compared with Session $1 ; \boldsymbol{b},{ }^{* *} p<0.01$ compared with ShA group and ${ }^{\#} p<0.05$ compared with LgA vehicle group.

\section{a}

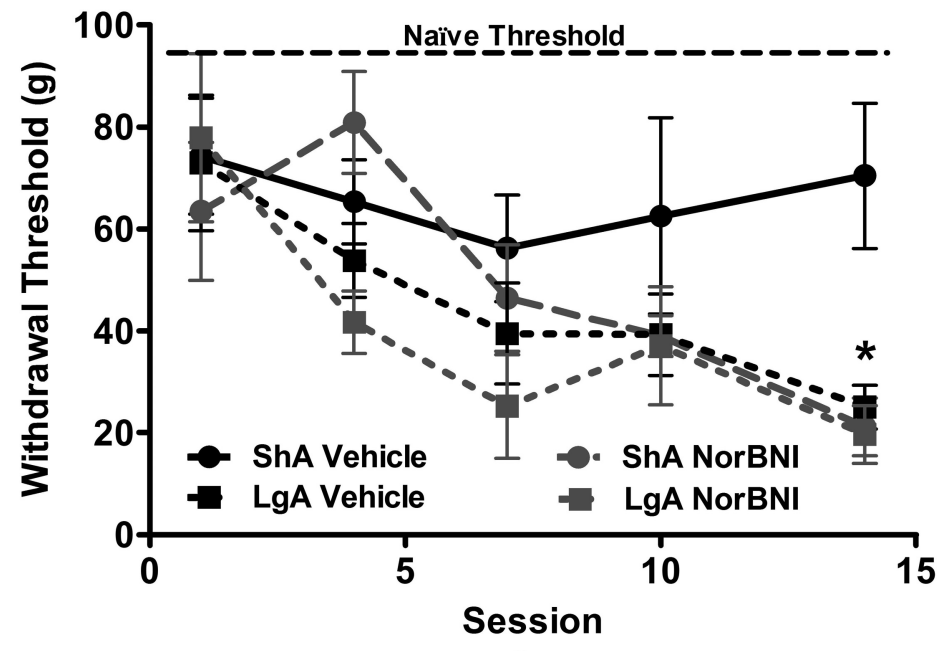

b

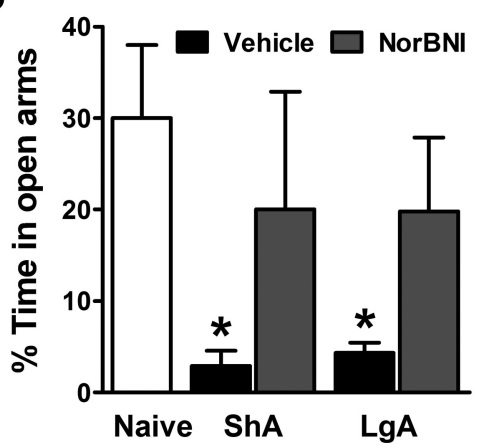

C

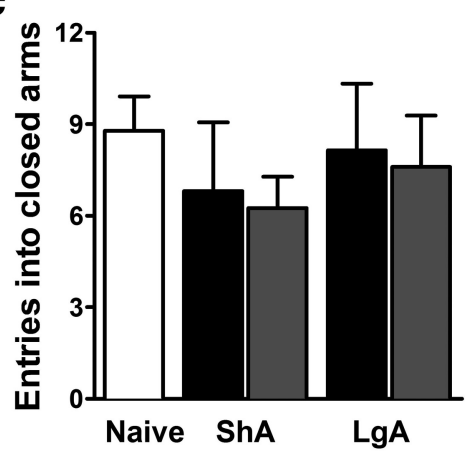

Figure 3. $\kappa$ Receptor antagonism reduced anxiety-like behavior but not mechanical hypersensitivity associated with heroin withdrawal. $\boldsymbol{a}$, Mechanical sensitivity measured by von Frey filament thresholds were tested over the course of heroin self-administration and escalation. The average for stable drug-naive thresholds is shown across the top. Thresholds progressively decreased over the period of $\mathrm{LgA}$ escalation, which prophylactic nor-BNI treatment failed to reverse. $n=5-8$ per group. ${ }^{*} p<0.05$ compared with ShA vehicle group. $\boldsymbol{b}$, Anxiety-like behavior on elevated plus maze was observed at the end of heroin escalation, reflected by reduced time spent on the open arms in heroin-exposed groups, an effect reversed by pretreatment with nor-BNI.c, Locomotor effects, reflected by the number of entries into the closed arms, were not altered across treatments. $n=5-8$ per group. ${ }^{*} p<0.05$ compared with naive controls.

significant increase in heroin intake compared with Session 1. The day following the last heroin escalation session, the motivation for heroin infusions was measured using a $6 \mathrm{~h}$ PR test. Compared with the ShA groups, both LgA groups exhibited increased heroin intake and breakpoints on the PR schedule (ac- cess: $\left.F_{(1,26)}=9.3, p<0.01\right)$. However, nor-BNI selectively reduced PR performance in the $\operatorname{LgA}$ group compared with saline, reducing intake and lever pressing (access $\times$ treatment interaction: $F_{(1,26)}=$ 3.5, $p<0.05$; Fig. 2b).

Opioid hypersensitivity was monitored by testing von Frey filament mechanical thresholds, measured every third selfadministration session throughout heroin escalation, just before the start of the session. All heroin self-administering groups maintained enhanced mechanical sensitivity, but vehicle-treated ShA rats maintained a stable threshold that did not significantly differ from that of naive rats, whose stable average is shown for comparison in Figure $3 a$ (top labeled line). Vehicle-treated LgA rats showed progressively increasing opioid hypersensitivity, with mechanical thresholds decreasing $\sim 4$-fold over a 3 week period. However, nor-BNI pretreatment did not alter the progression of opioid hypersensitivity in LgA rats and even exacerbated opioid hypersensitivity in ShA rats (session $\times$ treatment interaction: $\left.F_{(4,35)}=2.6, p<0.05\right)$.

At the completion of heroin escalation, just before measuring "escalated" PR intake (Fig. 2a), anxiety-like behavior associated with withdrawal was measured using the elevated plus maze. Compared with naive controls, heroin self-administering animals at $\sim 8 \mathrm{~h}$ into withdrawal showed significantly reduced time on the open arm, indicating an anxiety-like response regardless of heroin access (Fig. 3b). Importantly, nor-BNI reversed this anxiety-like phenotype 3 weeks after initial pretreatment (treatment: $F_{(4,23)}=2.9, p<0.05$ ). The treatment and heroin intake did not alter general locomotor behavior, reflected by the number of entries/crossings into the closed arms, which were comparable across all of the groups (Fig. 3c).

Experiment 2: Selective activation of KOR-dynorphin activity in the nucleus accumbens shell following heroin escalation

To examine whether this prevention of the transition to heroin dependence corresponds to regionally selective enhancement of endogenous KOR signaling, prodynorphin immunohistochemistry was performed in striatal coronal sections in naive, ShA, and LgA rats. We observed sparse cellbody staining in various cortical regions. However, staining within the nucleus accumbens was exclusively dense fiber staining (Fig. $4 a-c$ ). Therefore, averaged integrated density was used to analyze the nucleus accumbens core and shell across heroin access. Prodynorphin density was significantly increased in the nucleus accumbens core in all of the 
heroin self-administering groups (access: $F_{(2,66)}=5.9, p<0.01$; Fig. $\left.4 e\right)$, regardless of the level of heroin intake or severity of heroin dependence. Although prodynorphin density was elevated compared with naive controls, the lack of difference in prodynorphin content in the nucleus accumbens core between the ShA and LgA groups may be attributable to exposure to the selfadministration context, learning, or any amount of heroin exposure. Conversely, density within the nucleus accumbens shell was selectively increased only in LgA brains (access: $F_{(2,66)}=7.1, p<0.01$; Fig. $4 f$ ). Thus, the nucleus accumbens shell showed selectively elevated prodynorphin content in heroin-escalated rats, which may indicate a selective adaptation in the transition from heroin use to dependence.

Experiment 3: KOR-dynorphin activity in the nucleus accumbens shell mediates escalation of heroin intake To determine whether the regionally selective elevation of prodynorphin in the LgA group indicates a functional neural substrate by which the KOR-dynorphin system drives the escalation of heroin intake, norBNI was bilaterally injected into the nucleus accumbens shell ( $4 \mu \mathrm{g} / 0.5 \mathrm{ml} / \mathrm{side}) 4 \mathrm{~d}$ before the first session (Fig. $5 c$ ). Similar to systemic administration, local infusion of nor-BNI into the nucleus accumbens shell prevented significant escalation of heroin self-administration selectively in the LgA group, without altering initial LgA or stable ShA heroin intake (access $\times$ session $\times$ treatment interaction: $F_{(16,224)}=1.9, p<0.05$; Fig. $5 a$ ). This interruption of escalation was reflected in the subsequent PR test, in which intranucleus accumbens shell nor-BNI treatment significantly reduced the motivation for heroin intake in the LgA group (access $\times$ treatment interaction: $F_{(1,14)}=4.7$, $p<0.05$; Fig. $5 b$ ). Systemic nor-BNI failed to alter heroin hyperalgesia, and we did not track mechanical sensitivity during escalation in these groups. However, in contrast to systemic nor-BNI treatment, local infusion into the nucleus accumbens shell suppressed the escalation of drug intake, without improving anxiety-like behavior measured at the same time point during escalation as systemic treatment (Session 15; treatment: $p=0.42$; data not shown).

Experiment 4: blockade of KORdynorphin activity in the nucleus accumbens core increases heroin intake Given the enhanced prodynorphin content within the nucleus accumbens core in heroin self-administering rats, regardless

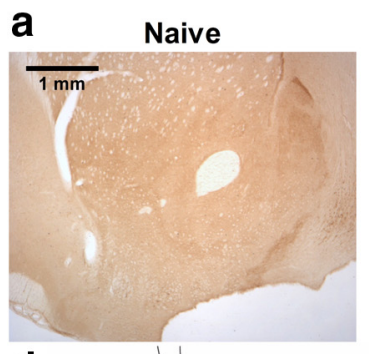

b
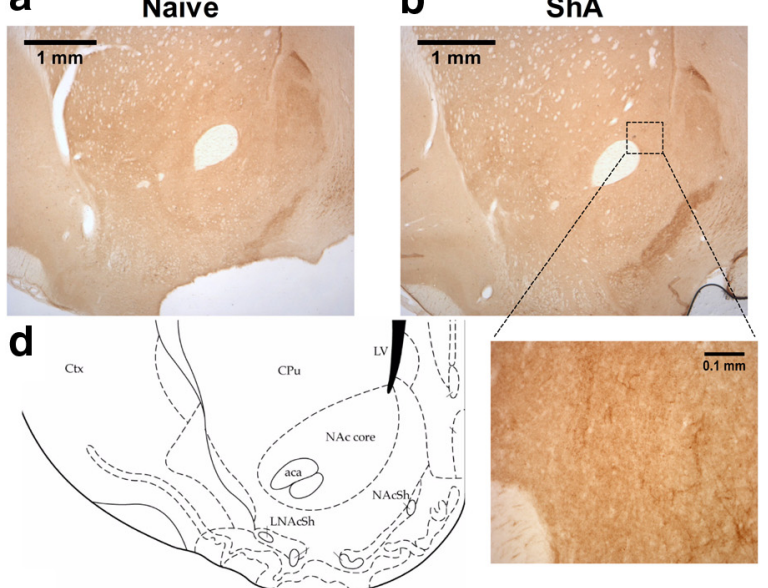

e Nucleus Accumbens Core

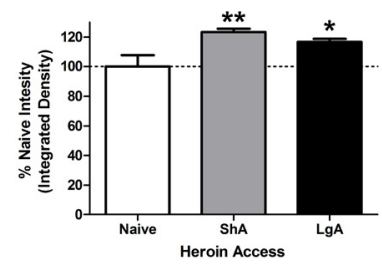

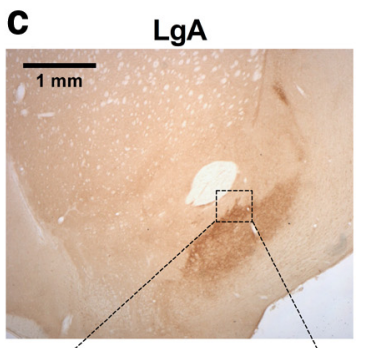

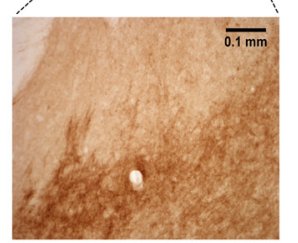

$f$
Figure 4. Immunohistochemical staining for prodynorphin content in the nucleus accumbens showed selective increases in the shell. $\boldsymbol{a}-\boldsymbol{c}$, Representative microscopic $(2.5 \times)$ samples from the naive, ShA heroin, and LgA heroin groups. Insets of fiber staining seen in the nucleus accumbens core are shown in a $10 \times$ inset below the ShA example image, and extensive fiber staining in the nucleus accumbens shell is shown in a $10 \times$ inset beneath the LgA example image. Prodynorphin reactivity in the nucleus accumbens was exclusively dense fiber staining, with increased area and intensity observed with increasing heroin exposure specifically in the shell. $\boldsymbol{d}$, Representative atlas schematic of the nucleus accumbens in example images. aca, Anterior commissure; CPu, caudate-putamen; Ctx, cortex; LNAcSh, lateral nucleus accumbens shell; $\mathrm{LV}$, lateral ventricle. $\boldsymbol{e}, \boldsymbol{f}$, Quantification of area-averaged color density within the nucleus accumbens core shows increases in both heroin-exposed groups, whereas prodynorphin content in the shell was selectively and significantly increased in the $L g A$ heroin self-administering group. $n=4$ subjects per group with bilateral triplicate slices run per tissue sample. ${ }^{*} p<0.05,{ }^{* *} p<0.01$, ${ }^{* * *} p<0.001$ compared with naive controls; ${ }^{*} p<0.05$ compared with ShA group.
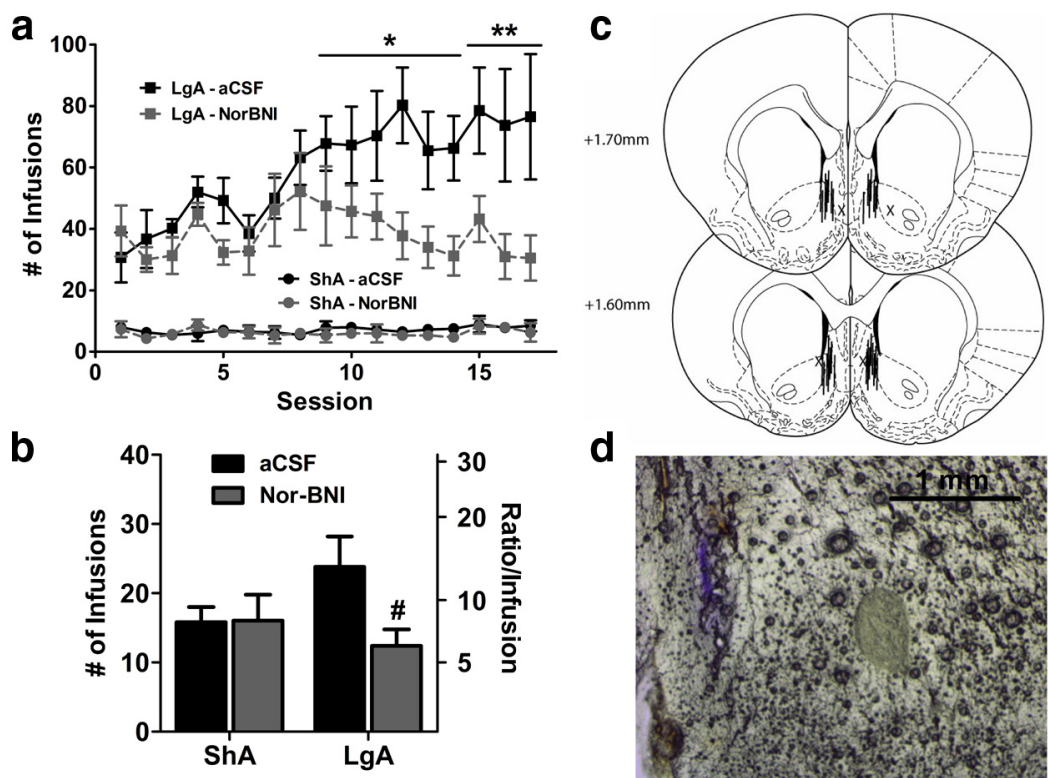

d

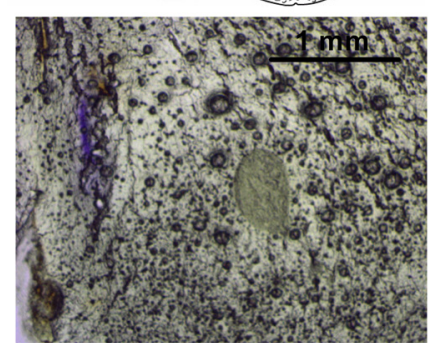

Figure 5. Bilateral nor-BNI infusion ( $4 \mu \mathrm{g} /$ side) into the nucleus accumbens shell prevented the escalation of heroin selfadministration. $\boldsymbol{a}$, Locally infused pretreatment with nor-BNI $4 \mathrm{~d}$ before the first session selectively prevented the escalation of intake in $12 \mathrm{~h} \mathrm{LgA}$ rats. $\boldsymbol{b}$, PR performance was selectively reduced in nor-BNl-treated LgA rats. The left axis shows total heroin infusions under PR schedule, and the right axis displays the final ratio achieved ("breakpoint"). c, Schematic diagram of injector placements of individual subjects in the nucleus accumbens shell. Solid lines represent included subjects, and X's represent excluded subjects. $\boldsymbol{d}$, Representative slice confirming placement at shell coordinates via Evans blue dye injection. $n=5-7$ per group. ${ }^{*} p<0.05,{ }^{* *} p<0.01$ compared with Session $1 ;{ }^{*} p<0.05$ compared with LgA vehicle group. 
a

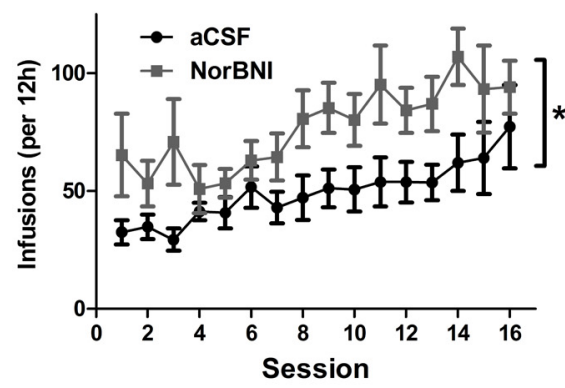

b

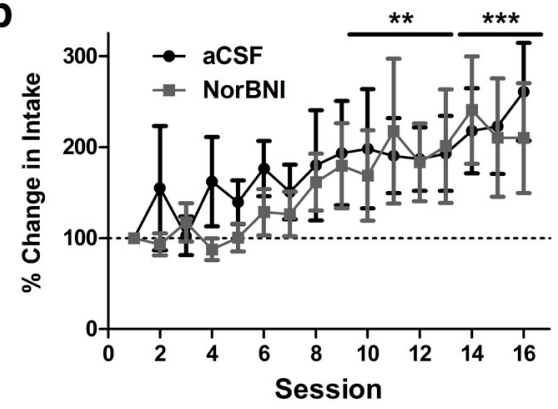

C
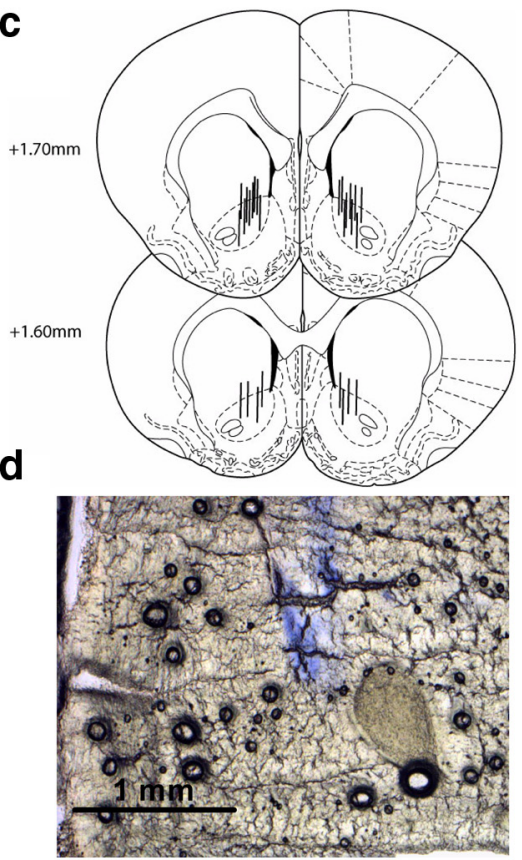

Figure 6. Bilateral nor-BNI infusion ( $4 \mu \mathrm{g} / \mathrm{side}$ ) into the nucleus accumbens core increases heroin self-administration, but not the escalation of heroin intake. $\boldsymbol{a}$, Locally infused pretreatment with nor-BNI $4 \mathrm{~d}$ before the first session increased heroin infusions from the first session onward. $\boldsymbol{b}$, Percentage change in heroin intake, with Session 1 representing 100\% for each rat, shows equivalent rates of heroin escalation in aCSF and nor-BNI-treated group. $c$, Schematic diagram of cannula placement in the nucleus accumbens. Lines represent injector positions of individual subjects. $\boldsymbol{d}$, Representative slice confirming placement at core coordinates via Evans blue dye injection. $n=6-7$ per group. $\boldsymbol{a},{ }^{*} p<0.05$ overall treatment effect. $\boldsymbol{b},{ }^{* *} p<0.01,{ }^{* * *} p<0.001$ compared with Session 1.

of access, heroin escalation was examined following local norBNI infusion ( $4 \mu \mathrm{g} / 0.5 \mathrm{ml} / \mathrm{side})$ into the core. In contrast to systemic and shell $\kappa$ opioid antagonism, core injection produced enhanced intake of heroin from the first session, and was persistently and significantly enhanced over the entire escalation period (treatment: $F_{(1,165)}=8.5, p<0.01$; Fig. $6 a$ ). Also in contrast to nucleus accumbens shell, core infusion of nor-BNI failed to prevent significant escalation of heroin intake. Upon examining the percentage change from Session 1, both groups escalated at similar rates, both core aCSF and nor-BNI groups demonstrating significant escalation from Session 9 onward (session: $F_{(15,165)}=$ 4.1, $p<0.001$; Fig. 6b). Examining the heroin intake under PR schedule subsequent to the final escalation session did not produce significantly different performances (infusions: aCSF, $24.7 \pm 4.0$; nor-BNI, $30.7 \pm 2.3 ; p=0.20$ ). Anxiety-like behavior was not altered by nor-BNI infusion into the nucleus accumbens core compared with aCSF (Session 16; treatment: $p=0.56$; data not shown).

\section{Discussion}

KOR antagonism effectively prevented the transition from stable, controlled heroin intake to excessive, increasing heroin intake as modeled in the ShA and LgA groups, respectively. The effects of KOR antagonism are effective when the antagonist is onboard before escalation, but it does not directly suppress heroin taking. The suppression of heroin self-administration was paralleled by reduced anxiety-like responses in KOR antagonist-treated rats. When examining potential brain regions where KOR signaling is specifically altered by the transition from stable to excessive heroin self-administration, the nucleus accumbens shell showed an increase in prodynorphin content only in the LgA heroin group. Local KOR antagonism in the nucleus accumbens shell prevented the escalation of heroin intake selectively in LgA rats, without abating anxiety-like behavior, suggesting that KOR-dynorphin activity in the nucleus accumbens shell is critical to the transition from stable to excessive heroin use.

The long-acting KOR antagonist nor-BNI prevented the escalation and progression of dependence in heroin self-administering rats with a singular prophylactic administration. Previous studies have shown that singular high doses of nor-BNI can produce longlasting antagonism of $\kappa$ opioid signaling when given systemically (Knoll et al., 2007; Wee and Koob, 2010), spinally (Jones and Holtzman, 1992), or intracerebroventricularly (Horan et al., 1992; Chartoff et al., 2012). This antagonism of $\kappa$ opioid signaling can last from 1 to 3 months (Potter et al., 2011), possibly through indirect inactivation of receptors via c-Jun N-terminal kinase (Bruchas et al., 2007). Pretreatment with nor-BNI, either given systemically or locally infused into the nucleus accumbens shell, effectively prevented escalation with neither route of administration showing signs of suppressing initial, nondependent intake. Conversely, nucleus accumbens core infusions altered initial intake without ultimately impacting the escalation of intake. Upon the escalation of heroin taking, LgA rats exhibited persistent increases in PR performance compared with ShA rats, reflecting an increased motivation to obtain heroin under an increasing workload. Pretreatment with nor-BNI prevented the increased PR performance following escalation, demonstrating a prevention of alteration in heroin's rewarding value over time and exposure. In a previous study, repeated PR testing in cocaine-dependent rats demonstrated gradual decreases in motivation with nor-BNI treatment (Wee et al., 2009). norBNI also effectively suppressed the escalated consumption of alcohol in alcohol-dependent, but not nondependent, rats (Walker et al., 2011). Common to all three drugs tested and coinciding with parallel studies in methamphetamine selfadministering rats (T. W. Whitfield, S. Wee, J. E. Schlosburg, L. F. Vendruscolo, S. Edwards, A. Gould, Y. Grant, E. F. Crawford, G. F. Koob, unpublished citation), KOR antagonism did not suppress FR1 or PR performance in nondependent ShA rats. The increased intake of subjects locally infused with norBNI in the accumbens core suggests $\kappa$ opioid signaling in the core modulates the general rewarding value, without altering the dynamic adaptations of extended drug use. Altogether, these results indicate that the dynorphin-KOR system provides a critical negative feedback mechanism during escalation, possibly affecting dopaminergic tone, which supports long-lasting allostatic changes in drug reinforcement.

Hyperalgesia or mechanical sensitivity is also hypothesized to be a factor in drug craving and intake, with the goal of relieving the pain associated with opioid withdrawal. However, our results demonstrated a disconnect between escalated heroin intake and concurrent mechanical hypersensitivity. 
This was also recently demonstrated with neurokinin-1, another stress-related receptor (Barbier et al., 2013), in which neurokinin-1 antagonists potently and effectively blocked heroin self-administration in both ShA-experienced and LgAexperienced groups without impacting the development of mechanical hypersensitivity. The escalation of heroin intake was paralleled by progressively increasing mechanical hypersensitivity, which has been shown to be sensitive to corticotropinreleasing factor (CRF) receptor antagonist treatment (Edwards et al., 2012). Given that dynorphin and KOR agonists are typically analgesic, it would be surprising if KOR antagonists reverse the hyperalgesia-like response to heroin use. Indeed, nor-BNI's effects on repeated morphine intake indicate that KOR antagonism might enhance and prolong antinociceptive tolerance (Sofuoglu et al., 1992) and even slightly exacerbate immediate somatic signs during precipitated withdrawal (Suzuki et al., 1992). Indeed, an inactive cleavage product, dynorphin A 2-17, was able to reduce somatic opiate withdrawal in rats without affecting conditioned place aversion (Shippenberg et al., 2000). Thus, the evidence demonstrates that the physical and motivational manifestations of opioid use may interact, but can be clearly dissociable through contributing neurotransmitter systems.

Prodynorphin immunohistochemistry using brains from rats with varying heroin experience showed that prodynorphin levels were elevated in the nucleus accumbens core, but this occurred regardless of heroin exposure. ShA rats showed elevated nucleus accumbens core prodynorphin, without exhibiting signs of compulsive heroin intake. LgA rats that showed escalated heroin intake also showed increased prodynorphin content in both the nucleus accumbens core and shell. Based on these findings, we locally infused nor-BNI into the nucleus accumbens core and shell, each showing responses congruent with changes in prodynorphin content. Core infusion of nor-BNI effectively altered heroin response from the first session, before the onset of escalation, while shell infusion solely suppressed the transition to dependence-like heroin seeking. These results are consistent with previous studies that demonstrated increases in nucleus accumbens shell prodynorphin mRNA during heroin self-administration (Solecki et al., 2009) and stress-induced heroin reinstatement (Zhou et al., 2013). Furthermore, KORs in the nucleus accumbens shell are situated in close proximity to dopamine transporters on presynaptic axons, which determine synaptic dopamine concentrations and the duration of release (Svingos et al., 2001). Stimulation of postsynaptic neurons increases the activation of cyclic adenosine monophosphate response element binding protein (CREB), which itself is hypothesized to promote dysphoric-like responses due to the transcriptional regulation of prodynorphin, in which depressive-like behavior caused by CREB overexpression is reversible by KOR antagonists (Newton et al., 2002). This sets up a model in which dynorphin exerts negative feedback on local dopaminergic neurotransmission (Carlezon et al., 2005).

Dopaminergic projections from the ventral tegmental area (VTA) to nucleus accumbens and prefrontal cortex (PFC) are commonly implicated in drug reward (Carlezon and Wise, 1996). Dynorphin appears to exert control over dopamine release in the nucleus accumbens shell via actions in both the nucleus accumbens shell and PFC. The control of dopamine release in the nucleus accumbens shell could be locally mediated by dynorphin, given our present immunohistochemical results that showed increases in terminal staining for prodynorphin in heroin-dependent rats. KORs in the VTA inhibit the activity of dopaminergic neurons, though apparently those particular VTA neurons do not project to the nucleus accumbens shell, but rather the PFC (Margolis et al., 2006). However, evidence suggests that serotonergic projections from the dorsal raphe to the nucleus accumbens shell produce the expression of aversive behaviors caused by KOR agonists (Land et al., 2009; Schindler et al., 2012). Further investigation and colabeling studies will be necessary to determine the synaptic characteristics and connections of the KORcontaining neurons within the nucleus accumbens shell.

Previous studies have examined the role of KORs on anxiety-like behavior associated with alcohol withdrawal (Schank et al., 2012; Valdez and Harshberger, 2012). nor-BNI effectively reversed the anxiogenic-like effects of heroin withdrawal in the elevated plus maze but not in animals that received local nor-BNI infusion into the nucleus accumbens. Although anxiety-like behavior associated with withdrawal could be hypothesized to contribute to escalation via negative reinforcement, the present results suggest that anxiety-like behavior also was mediated by neural substrates independent of escalated heroin intake. Thus, KOR antagonism in the nucleus accumbens shell can block the development of escalation in heroin intake and compulsive-like responding without altering hyperalgesic-like or anxiogenic-like responses, further reinforcing a selective motivational role of KOR systems in the nucleus accumbens initially hypothesized by Carlezon et al. (2005). The activation of KORs in the amygdala has been shown to control anxiety-like behavior caused by stress or CRF, a common component of brain stress activation in drug withdrawal (Bruchas et al., 2009). Previous studies (Solecki et al., 2009; Zhou et al., 2013) have identified, in addition to the nucleus accumbens shell, one other key structure with elevated prodynorphin mRNA expression. This structure is the central nucleus of the amygdala, which may mediate the anxiogeniclike effects of withdrawal and stress-induced relapse. The central nucleus of the amygdala is integral to the negative affective states associated with drug withdrawal and responsive to CRFstress activation (Koob, 2008).

In summary, the present study found that dynorphin content in the nucleus accumbens shell was enhanced during the escalation of heroin self-administration, modifying the adaptive changes produced by repeated drug infusions and preventing the increased motivation driving compulsive-like heroin seeking. Thus, in addition to reducing the stressinduced reinstatement of drug seeking, KOR antagonists may represent promising pharmacotherapeutics for the treatment of heroin addiction. Based on the present results and given its potential contraindication in the somatic aspects of opioid detoxification, KOR antagonist treatment may be most effective during protracted withdrawal in the prevention of negative affective symptoms and reestablishment of the addiction cycle. The comparable results obtained with alcohol (Nealey et al., 2011) and methamphetamine suggest that the KOR system may be a potential target for the treatment of drug addiction.

\section{References}

Barbier E, Vendruscolo LF, Schlosburg JE, Edwards S, Juergens N, Park PE, Misra KK, Cheng K, Rice KC, Schank J, Schulteis G, Koob GF, Heilig M (2013) The NK1 Receptor Antagonist L822429 Reduces Heroin Reinforcement. Neuropsychopharmacology 38:976-984. CrossRef Medline

Bruchas MR, Yang T, Schreiber S, Defino M, Kwan SC, Li S, Chavkin C (2007) Long-acting kappa opioid antagonists disrupt receptor signaling and produce noncompetitive effects by activating c-Jun N-terminal kinase. J Biol Chem 282:29803-29811. CrossRef Medline 
Bruchas MR, Land BB, Lemos JC, Chavkin C (2009) CRF1-R activation of the dynorphin/kappa opioid system in the mouse basolateral amygdala mediates anxiety-like behavior. PloS One 4:e8528. CrossRef Medline

Cappendijk SL, Hurd YL, Nylander I, van Ree JM, Terenius L (1999) A heroin-, but not a cocaine-expecting, self-administration state preferentially alters endogenous brain peptides. Eur J Pharmacol 365:175-182. CrossRef Medline

Carlezon WA Jr, Wise RA (1996) Rewarding actions of phencyclidine and related drugs in nucleus accumbens shell and frontal cortex. J Neurosci 16:3112-3122. Medline

Carlezon WA Jr, Duman RS, Nestler EJ (2005) The many faces of CREB. Trends Neurosci 28:436-445. CrossRef Medline

Chartoff E, Sawyer A, Rachlin A, Potter D, Pliakas A, Carlezon WA (2012) Blockade of kappa opioid receptors attenuates the development of depressive-like behaviors induced by cocaine withdrawal in rats. Neuropharmacology 62:167-176. CrossRef Medline

Chavkin C, James IF, Goldstein A (1982) Dynorphin is a specific endogenous ligand of the kappa opioid receptor. Science 215:413-415. CrossRef Medline

Clarke TK, Ambrose-Lanci L, Ferraro TN, Berrettini WH, Kampman KM, Dackis CA, Pettinati HM, O'Brien CP, Oslin DW, Lohoff FW (2012) Genetic association analyses of PDYN polymorphisms with heroin and cocaine addiction. Genes Brain Behav 11:415-423. CrossRef Medline

Edwards S, Vendruscolo LF, Schlosburg JE, Misra KK, Wee S, Park PE, Schulteis G, Koob GF (2012) Development of mechanical hypersensitivity in rats during heroin and ethanol dependence: alleviation by CRF(1) receptor antagonism. Neuropharmacology 62:1142-1151. CrossRef Medline

Gerra G, Leonardi C, Cortese E, D’Amore A, Lucchini A, Strepparola G, Serio G, Farina G, Magnelli F, Zaimovic A, Mancini A, Turci M, Manfredini M, Donnini C (2007) Human kappa opioid receptor gene (OPRK1) polymorphism is associated with opiate addiction. Am J Med Genet B Neuropsychiatr Genet 144B:771-775. CrossRef Medline

Horan P, Taylor J, Yamamura HI, Porreca F (1992) Extremely long-lasting antagonistic actions of nor-binaltorphimine (nor-BNI) in the mouse tailflick test. J Pharmacol Exp Ther 260:1237-1243. Medline

Jones DN, Holtzman SG (1992) Long term kappa-opioid receptor blockade following nor-binaltorphimine. Eur J Pharmacol 215:345-348. CrossRef Medline

Knoll AT, Meloni EG, Thomas JB, Carroll FI, Carlezon WA Jr (2007) Anxiolytic-like effects of kappa-opioid receptor antagonists in models of unlearned and learned fear in rats. J Pharmacol Exp Ther 323:838-845. CrossRef Medline

Koob GF (2008) A role for brain stress systems in addiction. Neuron 59:1134. CrossRef Medline

Land BB, Bruchas MR, Schattauer S, Giardino WJ, Aita M, Messinger D, Hnasko TS, Palmiter RD, Chavkin C (2009) Activation of the kappa opioid receptor in the dorsal raphe nucleus mediates the aversive effects of stress and reinstates drug seeking. Proc Natl Acad Sci U S A 106:1916819173. CrossRef Medline

Mague SD, Pliakas AM, Todtenkopf MS, Tomasiewicz HC, Zhang Y, Stevens WC Jr, Jones RM, Portoghese PS, Carlezon WA Jr (2003) Antidepressant-like effects of kappa-opioid receptor antagonists in the forced swim test in rats. J Pharmacol Exp Ther 305:323-330. CrossRef Medline

Margolis EB, Lock H, Chefer VI, Shippenberg TS, Hjelmstad GO, Fields HL (2006) Kappa opioids selectively control dopaminergic neurons projecting to the prefrontal cortex. Proc Natl Acad Sci U S A 103:2938-2942. CrossRef Medline

Munro TA, Berry LM, Van't Veer A, Béguin C, Carroll FI, Zhao Z, Carlezon WA Jr, Cohen BM (2012) Long-acting kappa opioid antagonists norBNI, GNTI and JDTic: pharmacokinetics in mice and lipophilicity. BMC Pharmacology 12:5. CrossRef Medline

Nealey KA, Smith AW, Davis SM, Smith DG, Walker BM (2011) kappaopioid receptors are implicated in the increased potency of intraaccumbens nalmefene in ethanol-dependent rats. Neuropharmacology 61:35-42. CrossRef Medline

Negus SS, Henriksen SJ, Mattox A, Pasternak GW, Portoghese PS, Takemori AE, Weinger MB, Koob GF (1993) Effect of antagonists selective for mu, delta and kappa opioid receptors on the reinforcing effects of heroin in rats. J Pharmacol Exp Ther 265:1245-1252. Medline
Newton SS, Thome J, Wallace TL, Shirayama Y, Schlesinger L, Sakai N, Chen J, Neve R, Nestler EJ, Duman RS (2002) Inhibition of cAMP response element-binding protein or dynorphin in the nucleus accumbens produces an antidepressant-like effect. J Neurosci 22:1088310890. Medline

Nylander I, Vlaskovska M, Terenius L (1995) The effects of morphine treatment and morphine withdrawal on the dynorphin and enkephalin systems in Sprague-Dawley rats. Psychopharmacology (Berl) 118:391-400. CrossRef Medline

Pfeiffer A, Brantl V, Herz A, Emrich HM (1986) Psychotomimesis mediated by kappa opiate receptors. Science 233:774-776. CrossRef Medline

Potter DN, Damez-Werno D, Carlezon WA Jr, Cohen BM, Chartoff EH (2011) Repeated exposure to the kappa-opioid receptor agonist salvinorin A modulates extracellular signal-regulated kinase and reward sensitivity. Biol Psychiatry 70:744-753. CrossRef Medline

Redila VA, Chavkin C (2008) Stress-induced reinstatement of cocaine seeking is mediated by the kappa opioid system. Psychopharmacology (Berl) 200:59-70. CrossRef Medline

Rimoy GH, Wright DM, Bhaskar NK, Rubin PC (1994) The cardiovascular and CNS effects in the human of U-62066E. A selective opioid receptor agonist. Eur J Clin Pharmacol 46:203-207. Medline

Schank JR, Goldstein AL, Rowe KE, King CE, Marusich JA, Wiley JL, Carroll FI, Thorsell A, Heilig M (2012) The kappa opioid receptor antagonist JDTic attenuates alcohol seeking and withdrawal anxiety. Addict Biol 17:634-647. CrossRef Medline

Schindler AG, Messinger DI, Smith JS, Shankar H, Gustin RM, Schattauer SS, Lemos JC, Chavkin NW, Hagan CE, Neumaier JF, Chavkin C (2012) Stress produces aversion and potentiates cocaine reward by releasing endogenous dynorphins in the ventral striatum to locally stimulate serotonin reuptake. J Neurosci 32:17582-17596. CrossRef Medline

Shippenberg TS, Herz A (1986) Differential effects of mu and kappa opioid systems on motivational processes. NIDA Res Monogr 75:563-566. Medline

Shippenberg TS, Funada M, Schutz CG (2000) Dynorphin A (2-17) attenuates the unconditioned but not the conditioned effects of opiate withdrawal in the rat. Psychopharmacology (Berl) 151:351-358. CrossRef Medline

Sofuoglu M, Portoghese PS, Takemori AE (1992) Maintenance of acute morphine tolerance in mice by selective blockage of kappa opioid receptors with norbinaltorphimine. Eur J Pharmacol 210:159-162. CrossRef Medline

Solecki W, Ziolkowska B, Krowka T, Gieryk A, Filip M, Przewlocki R (2009) Alterations of prodynorphin gene expression in the rat mesocorticolimbic system during heroin self-administration. Brain Res 1255:113-121. CrossRef Medline

Suzuki T, Narita M, Takahashi Y, Misawa M, Nagase H (1992) Effects of nor-binaltorphimine on the development of analgesic tolerance to and physical dependence on morphine. Eur J Pharmacol 213:91-97. CrossRef Medline

Svingos AL, Chavkin C, Colago EE, Pickel VM (2001) Major coexpression of kappa-opioid receptors and the dopamine transporter in nucleus accumbens axonal profiles. Synapse 42:185-192. CrossRef Medline

Tjon GH, Voorn P, Vanderschuren LJ, de Vries TJ, Michiels NH, Jonker AJ, Klop H, Nestby P, Mulder AH, Schoffelmeer AN (1997) Delayed occurrence of enhanced striatal preprodynorphin gene expression in behaviorally sensitized rats: differential long-term effects of intermittent and chronic morphine administration. Neuroscience 76:167-176. Medline

Todtenkopf MS, Marcus JF, Portoghese PS, Carlezon WA Jr (2004) Effects of kappa-opioid receptor ligands on intracranial self-stimulation in rats. Psychopharmacology (Berl) 172:463-470. CrossRef Medline

United Nations Office for Drug Control and Crime Prevention (2012) World Drug Report 2012. Vienna: United Nations.

Valdez GR, Harshberger E (2012) Kappa opioid regulation of anxiety-like behavior during acute ethanol withdrawal. Pharmacol Biochem Behav 102:44-47. CrossRef Medline

Vendruscolo LF, Schlosburg JE, Misra KK, Chen SA, Greenwell TN, Koob GF (2011) Escalation patterns of varying periods of heroin access. Pharmacol Biochem Behav 98:570-574. CrossRef Medline

Walker BM, Koob GF (2008) Pharmacological evidence for a motivational role of kappa-opioid systems in ethanol dependence. Neuropsychopharmacology 33:643-652. CrossRef Medline 
Walker BM, Zorrilla EP, Koob GF (2011) Systemic kappa-opioid receptor antagonism by nor-binaltorphimine reduces dependence-induced excessive alcohol self-administration in rats. Addict Biol 16:116-119. CrossRef Medline

Wee S, Koob GF (2010) The role of the dynorphin-kappa opioid system in the reinforcing effects of drugs of abuse. Psychopharmacology (Berl) 210: 121-135. CrossRef Medline

Wee S, Orio L, Ghirmai S, Cashman JR, Koob GF (2009) Inhibition of kappa opioid receptors attenuated increased cocaine intake in rats with extended access to cocaine. Psychopharmacology (Berl) 205:565-575. CrossRef Medline

Weissman BA, Zamir N (1987) Differential effects of heroin on opioid levels in the rat brain. Eur J Pharmacol 139:121-123. CrossRef Medline

Xi ZX, Fuller SA, Stein EA (1998) Dopamine release in the nucleus accum- bens during heroin self-administration is modulated by kappa opioid receptors: an in vivo fast-cyclic voltammetry study. J Pharmacol Exp Ther 284:151-161. Medline

Yuferov V, Fussell D, LaForge KS, Nielsen DA, Gordon D, Ho A, Leal SM, Ott J, Kreek MJ (2004) Redefinition of the human kappa opioid receptor gene (OPRK1) structure and association of haplotypes with opiate addiction. Pharmacogenetics 14:793-804. CrossRef Medline

Zapata A, Shippenberg TS (2006) Endogenous kappa opioid receptor systems modulate the responsiveness of mesoaccumbal dopamine neurons to ethanol. Alcohol Clin Exp Res 30:592-597. CrossRef Medline

Zhou Y, Leri F, Grella SL, Aldrich JV, Kreek MJ (2013) Involvement of dynorphin and kappa opioid receptor in yohimbine-induced reinstatement of heroin seeking in rats. Synapse 67:358-361. CrossRef Medline 